\title{
BMJ Open Timing of first antenatal care contact, its associated factors and state-level analysis in Nigeria: a cross-sectional assessment of compliance with the WHO guidelines
}

\author{
Adeniyi Francis Fagbamigbe (1) ,,2 Olugbenga Olaseinde, ${ }^{3}$ \\ Omon Stellamaris Fagbamigbe (iD ${ }^{4}$
}

To cite: Fagbamigbe AF, Olaseinde 0, Fagbamigbe 0S. Timing of first antenatal care contact, its associated factors and state-level analysis in Nigeria: a cross-sectional assessment of compliance with the WHO guidelines. BMJ Open 2021;11:e047835. doi:10.1136/ bmjopen-2020-047835

- Prepublication history for this paper is available online. To view these files, please visit the journal online (http://dx.doi org/10.1136/bmjopen-2020047835).

Received 12 December 2020 Accepted 12 August 2021

Check for updates

(c) Author(s) (or their employer(s)) 2021. Re-use permitted under CC BY-NC. No commercial re-use. See rights and permissions. Published by BMJ.

${ }^{1}$ Epidemiology and Medical Statistics, University of Ibadan College of Medicine, Ibadan, Oyo, Nigeria

${ }^{2}$ Division of Population and Behavioral Sciences, School of Medicine, University of St. Andrews, St. Andrews, UK ${ }^{3}$ Department of Sociology, Adekunle Ajasin University, Akungba-Akoko, Nigeria ${ }^{4}$ Portsmouth Business School, University of Portsmouth, Portsmouth, UK

Correspondence to

Dr Adeniyi Francis Fagbamigbe; franstel74@yahoo.com

\section{ABSTRACT}

Objectives To assess the compliance of WHO guidelines on the timeliness of antenatal care (ANC) initiation in Nigeria and its associated factors and to provide subcountry analysis of disparities in the timing of the first ANC in Nigeria.

Design Cross-sectional.

Setting Nationally representative data of most recent pregnancies between 2013 and 2018 in Nigeria.

Participants Women with pregnancies within 5 years before the study.

Primary and secondary outcome measures The outcome variable was the trimesters of the first ANC contact. Data were analysed using descriptive statistics, bivariable and multivariable multinomial logistic regression at $5 \%$ significance level.

Results Of all the 21785 respondents, $75 \%$ had at least one ANC contact during their most recent pregnancies within the five years preceding the data collection. Among which $24 \%$ and $63 \%$ started in the first and second trimester, respectively. The proportion who started ANC in the first trimester was highest in Benue (44.5\%), Lagos (41.4\%) and Nasarawa (39.3\%) and lowest in Zamfara (7.6\%), Kano (7.4\%) and Sokoto (4.8\%). Respondents aged $40-49$ years were $65 \%$ (adjusted relative risk ratio (aRRR: $1.65,95 \% \mathrm{Cl}: 1.10$ to 2.45 ) more likely to initiate ANC during the first trimester of pregnancy relative to those aged 15-19 years. Although insignificant, women who participate in their healthcare utilisation were $4 \%$ (aRRR: 1.04, $95 \% \mathrm{Cl}: 0.90$ to 1.20) times more likely to have early initiation of ANC. Other significant factors were respondents' and spousal educational attainment, household wealth quintiles, region of residence, ethnicity, religion and birth order.

Conclusions Only a quarter of pregnant women, initiated ANC contact during the first trimester with wider disparities across the states in Nigeria and across the background characteristics of the pregnant women. There are needs to enhance women's autonomy in healthcare utilisation. Concerted efforts on awareness creation and empowerment for women by all stakeholders in maternal and child healthcare are antidotes for early ANC contact initiation.

\section{Strengths and limitations of this study}

- The findings are generalisable and timely as the data used were nationally representative of the women of childbearing age in Nigeria.

- Our study is novel as it provided state-level comparison of adherence to the timeliness of antenatal care (ANC) contacts as stipulated in the WHO guidelines.

- We used cross-sectional data which limited our choice of explanatory variables and only established association but not causality.

- Recall bias might have set in as some respondents were illiterate and most respondents had to recall when they initiated ANC contacts, except few cases found on ANC cards.

\section{INTRODUCTION}

Globally, antenatal care (ANC) remains an invaluable approach to preventive care for ensuring positive maternal and infant health outcomes. A global infant mortality rate reduction by over $50 \%$ from 1990 estimate of 65 deaths per 1000 live births to 29 deaths in 2017 and the annual infant deaths decline by half from 8.8 million deaths to 4.1 million over thesame period had been reported to have coincided with substantial improvement in ANC utilisation worldwide. ${ }^{1}$ Furthermore, a progress report on global maternal health from 2000 to 2017 showed tremendous improvement with a $38 \%$ decline in maternal mortality ratio from the year 2000 estimate of 342 deaths to 211 deaths per 100000 live births in 2017. ${ }^{2}$ Nonetheless, evidence still shows that about 303000 pregnancy-related and childbirth-related deaths were recorded among women and adolescent girls in 2015 . $^{3}$

Keeping up with the global trend of positive achievements in maternal and infant health remains a major issue of concern in 
sub-Saharan Africa (SSA). In 2015, the United Nations and the WHO estimates show that the SSA countries accounted for over $90 \%$ of all global maternal deaths and according to UNICEF, approximately half of all global child deaths occurred in the region in 2018. ${ }^{3-5}$ Also, the highest neonatal mortality rate was in SSA in 2019 while a child born in the region is 10 times more likely to die in the first month of life than those born in a high-income country. ${ }^{16}$ The situation in Nigeria is perhaps more worrisome than in most African countries. Nigeria was listed among countries with no appreciable progress in the maternal and infant health indicator in the recent assessment of Sustainable Development Goals (SDG). ${ }^{7}$ The 2015 WHO assessment showed that Nigeria accounted for about $20 \%$ of world maternal deaths. There are 1 in 22 chances for a pregnant woman in Nigeria to die from pregnancy-related and childbirth-related complications compared with 1 in 5400 in the developed countries. ${ }^{35}$ On a daily basis, a total of 257 deaths occur among babies within their first month of life in Nigeria, this translates to 262000 infant deaths annually. ${ }^{8-10}$

However, WHO estimated that two-thirds of infant deaths are preventable if proper measures were taken, and danger signs taught during pregnancy (WHO 2016). Similarly, literature is replete that adequate and timely implementation of ANC protocols could contribute to the aversion of these preventable maternal and infant deaths. ${ }^{11-14}$ These studies showed that most of the pregnancy-related and childbirth-related deaths and other negative pregnancy outcomes may be prevented if timely and adequate precautionary measures are taken during ANC contacts. ANC is effective in the early detection and management of risky pregnancy conditions which could lead to morbidity or mortality for both the pregnant women and unborn children before, during or after delivery. ${ }^{15-18}$

Taking cognizance of evidence that affirms that compliance to ANC protocol ensures the safety of mother and baby throughout pregnancy, WHO recommended early initiation of ANC attendance, a minimum number of ANC contacts and a minimum standard of care for the effective operationalisation of ANC services. ${ }^{19}$ The 2016 WHO ANC model was birthed from the review of existing ANC protocols to strengthen the maternal and child health system. ${ }^{19}$ The model recommended that the first contact should be during the first trimester. This is in line with the findings that the first 3 months of pregnancy is very crucial in the management of health issues that may lead to complications for mother and baby in the later period. ${ }^{20-24}$ It is important to present the pregnancy for medical assessment, treatment and advice during this period to ensure safe delivery. ${ }^{23}$ Despite the reported advantages of early commencement of ANC, many pregnant women start ANC late.

Several factors have been reported to be associated with the timing of the first ANC contact in the literature. They include maternal age, women's level of education, marital status, ethnicity, women's involvement in the decision about their use of healthcare facilities, number of previous pregnancies, women's employment status, household's wealth, region and residence, and proximity to a health facility. ${ }^{2025}$ Other identified factors are husband's educational attainment, ${ }^{27}{ }^{28}$ parity, ${ }^{25} 29$ region and place of residence ${ }^{22}$ as well as women employment status. ${ }^{30}$ The timing of the first ANC contacts may also influence the number of ANC contacts made. The WHO recommendations in 2016 for a positive pregnancy experience also refer to the number of ANC received: the recommendation shifted from the focused model of four ANC visits to an expanded model of eight ANC contacts. In Nigeria, according to Fagbamigbe $e t a l$, only a quarter of pregnant women had no ANC contact, $38 \%$ had 4-7 visits and $20 \%$ up to 8 ANC contacts. ${ }^{31}$

The current study is designed to provide an up-to-date assessment of the timeliness of ANC initiation in Nigeria and the factors that drive the timing of the first ANC contact. Also, this study serves as a response to the United Nations call for continuous monitoring and evaluation of countries' closeness to the achievement of the SDGs. ${ }^{7}$ The study assessed the attainment of the SDG-3 that was set to 'ensure healthy lives and promote well-being for all at all ages'. ${ }^{7}$ Particularly, the current study will help elucidate Nigeria's preparedness to meeting the SDG-3: Target-3.1: 'By 2030, end preventable deaths of newborns and children under 5 years of age, with all countries aiming to reduce neonatal mortality to at least as low as 12 per 1000 live births and under-5 mortality to at least as low as 25 per 1000 live births' ${ }^{7}$ Also, we provided a within-country analysis of assessment and disparities in the timing of first ANC contacts across the 37 States in Nigeria as required in the assessment of SDGs. This study examined the compliance with WHO recommended standards on the timing of first ANC contact and identified the associated factors using nationally representative data of most recent pregnancies in Nigeria. We suggested pathways for the improvement of maternal and child health outcomes in Nigeria.

\section{METHODOLOGIES}

\section{Study setting}

The study setting is Nigeria. Nigeria is divided into 36 states and the Federal Capital Territory for administration purposes as shown in figure 1 . The states are further grouped into six regions. The states are are made up of local government areas (LGAs), and each LGA is divided into local administrative units. The LGAs are subdivided into convenient areas, for election purposes, called census enumeration areas (EAs).

\section{Data source}

We analysed the data collected among women of reproductive age in Nigeria. We used secondary data from the 2018 Nigeria Demographic Health Survey (NDHS). The NDHS is one in the series of surveys conducted by Inner City Fund (ICF) Macro International, Calverton, Maryland, USA, in conjunction with the Nigeria National 


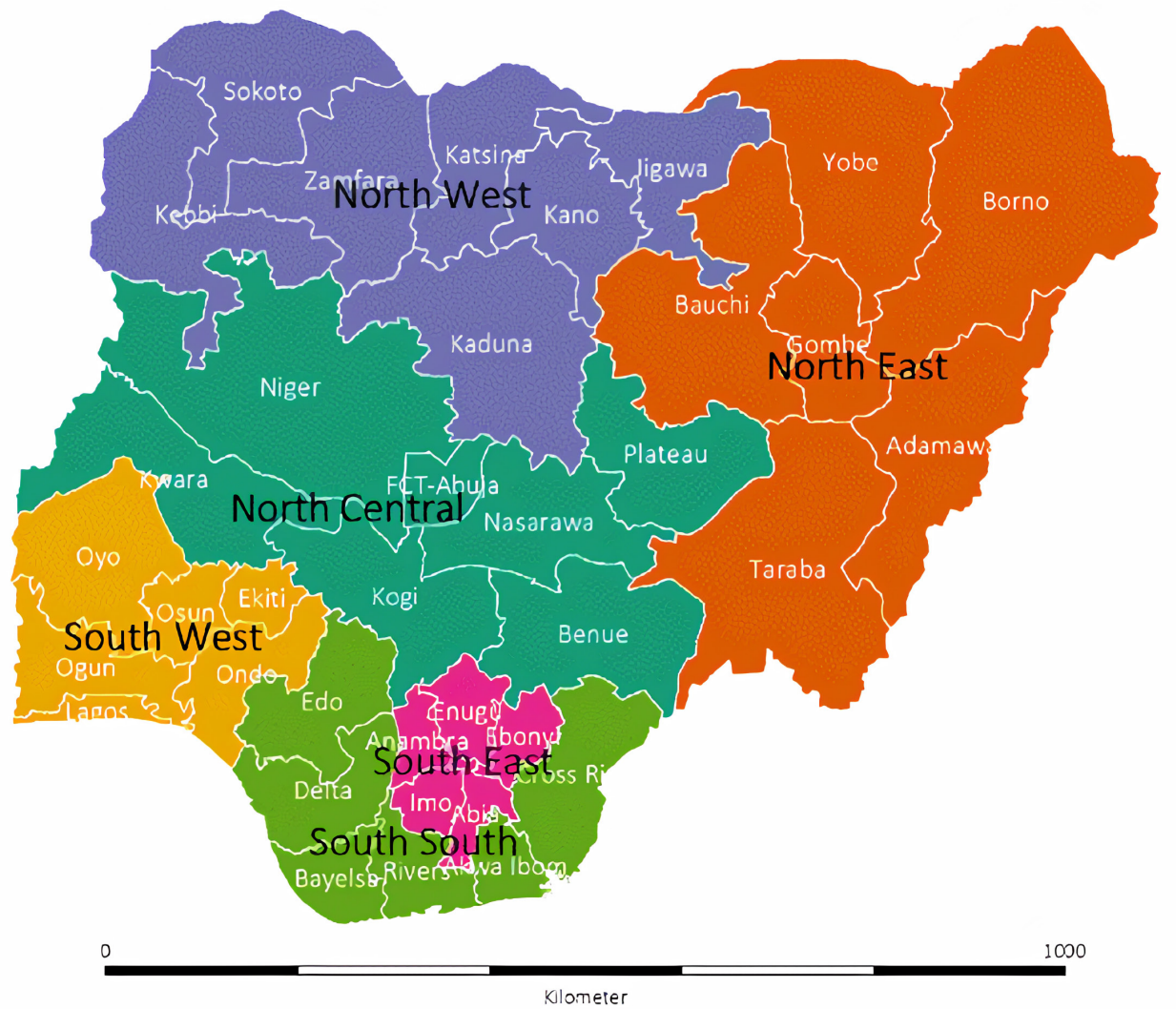

Figure 1 Map of Nigeria showing the 36 states, the federal capital territory, by the geopolitical zones.

Population Commission (NPC). ${ }^{32}$ The DHS data are cross-sectional in design and nationally representative household surveys. DHSs are conducted every 5 years in low-income and middle-income countries.

\section{Sampling techniques}

Two-stage sampling procedures were used for the 2018 NDHS survey. The sampling frame is the Population and Housing Census of the Federal Republic of Nigeria which was conducted in 2006 by the Nigeria NPC. The primary sampling unit referred to as a cluster are the EAs in the census frame. In each state, samples of EAs were selected independently in a two-stage selection. At the first stage, 38 EAs were selected with probability proportional to EA size in each state. At the second stage, 30 households were selected in every selected EAs using equal probability of systematic sampling. All eligible women of reproductive age (15-49 years) in all the selected households were interviewed. Sampling weights were applied in the analyses to account for the differences in response rates and population sizes of the states. A total of 41821 women aged 15-49 years were interviewed in the 2018 NDHS. ${ }^{32}$

\section{The data and the participants}

All eligible respondents were asked if they had any pregnancy or birth within 5 years preceding the survey. Those who answered in affirmative to haven had at least a birth within the preceding 5 years were asked questions on the number of ANC contacts made, the onset of the ANC visits, and the ANC provider etc for the pregnancy starting from the most recent. Our analysis is based on the information on the most recent pregnancies of each of the respondents. A total of 21785 women provided relevant information. Of these 21785 women, 16448 (75.5\%) attended ANC and were thus included in the final analysis.

\section{Variables}

The outcome variable is the timing of the first ANC visit among women. The time of the first ANC was reported in months by the mother and was grouped as first trimester (early initiation), second trimester (late initiation) and third trimester (very late initiation). We grouped the States in Nigeria into two: below $85 \%$ or 'greater than or equal to' $85 \%$ global 'no antenatal contact' prevalence. ${ }^{133}$ The states' performances regarding the proportion of women who initiated ANC visits in the first trimester during the most recent pregnancy is presented, with the states grouped into having $0 \%-33 \%, 34 \%-67 \%$ and $>67 \%$ early ANC visits.

Based on existing literature,${ }^{234-36}$ the independent variables used in this study are maternal age (15-19, 20-24, 25-29, 30-39, 40-49 years), educational attainment (no education, primary, secondary and higher), spouse educational attainment (no education, primary, secondary and higher), employment status (currently employed vs unemployed), spouse employment status (currently employed vs unemployed), access to media (at least one of radio, television, newspaper or not), household wealth tertile (low, middle and high), women's autonomy using 
who decides respondents healthcare utilisation (respondent alone, respondent/spouse and spouse alone). Other included independent variables are birth interval (firstborn, $<36$ months and $\geq 36$ months), birth order (1, 2, 3, 4 and $5+$ ), number of children ever born (none, 1-2, 3-4, $4+$ ), current marital status (currently married or living together, divorced/separated/widowed, never married), place of residence (rural vs urban), religion (Islam, Christian, others) and ethnicity (Hausa/Fulani, Igbo, Yoruba and others). Family mobility (had stayed less than 5 years at residence or not), wanted child when became pregnant (wanted then, wanted later, or wanted not more), household headship (male vs female), health insurance coverage (yes vs no), acceptance of wife-beating (yes vs no).

We also assessed four community-level factors in the descriptive analysis. The communities are synonymus to the EAs. The four factors are the community poverty rate (high or low), community unemployment rate (high vs low), community illiteracy rate (high vs low) and community media access rate (high vs low). We computed the neighbourhood socioeconomic status disadvantage as a composite score using principal component analysis and grouped into lowest, middle and highest categories. It is the proportion of respondents within each community with no media access, who are illiterates, who are poor and who are unemployed. The 'xtile' function in Stata V.16 was used to categorise the already provided wealth index scores (V.191) in the DHS data into three tertiles.

\section{Statistical methods}

Descriptive statistics, bivariable and multivariable multinomial logistic regression were used. The 'SVY' command for survey data in Stata V.16 was used to adjust for the study design used and the sample weights. Frequency tables showing percentages were used to describe the distribution of study respondents' characteristics and we cross-classified the outcome variables by the respondents' characteristics (table 1). Graphs and maps were produced using Microsoft Office 365 Excel and PowerPoint editable maps, respectively.

We used the 'multinomial logistic' command in Stata to implement bivariable and multivariable regression models. It is a procedure for estimating the risk ratio (RR) of factors associated with the outcome variables. Variables that were significant at $\mathrm{p}<0.20$ were included in the multivariable model. ${ }^{31}$

The multinomial logistic regression model computes the maximum-likelihood estimates of the probability of success of an event. In the binary logistic regression, the ORs are computed as the ratio of odds of success divided by the odds of failure, the $i^{\text {th }}$ coefficient is $\phi_{i}=\exp \left(b_{i}\right)$ with SE $s_{i}^{\phi}=\phi_{i} s_{i}$, where $s_{i}$ is the SE of $b_{i}$ estimated using the logit function. Assuming that the predicted index of the $j^{\text {th }}$ observation is defined as $X_{i} b$. The predicted probability of a positive outcome is

$$
P_{j}\left(y_{j} \neq 0 \mid X_{j}\right)=\frac{\exp \left(X_{i} b\right)}{1+\exp \left(X_{i} b\right)}(1) .
$$

Whereas, multinomial logistic regression is used for the categorical dependent variable, with three or more categories. If y has three outcomes 1, 2 and 3 whereby ' 3 ' is not necessarily greater than ' 1 ' or ' 2 '. Then, multinomial logistic regression is useful in modelling the nominal outcome variables. ${ }^{37}$

The relative probability of any of the levels, say $\mathrm{y}=2$ to the base outcome, say $\mathrm{y}=1$ is $\frac{p(y=2)}{p(y=1)}=e^{X \beta^{(2)}}$ which is the relative risk ratio (RRR). Assuming that $X$ and $\beta_{k}^{(2)}$ are vectors equal to $\left(x_{1}+x_{2}+\ldots x_{i} \ldots \ldots+x_{k}\right)$ and $\left(\beta_{1}^{(2)}+\beta_{2}^{(2)}+\ldots+\beta_{i}^{(2)}+\ldots \beta_{k}^{(2)}\right)$, the ratio of the relative risk (RR) for a one-unit change in $\mathrm{x}_{\mathrm{t}}$ is

$$
\frac{e^{\beta_{1}^{(2)} x_{1}}+\ldots+e^{\beta_{i}^{(2)} x_{(i+1)}}+\ldots \ldots+e_{k}^{\beta_{k}^{(2)} x_{k}}}{e^{\beta_{1}^{(2)} x_{1}}+\ldots+e^{\beta_{i}^{(2)} x_{i}}+\ldots \ldots+e_{k}^{\beta_{k}^{(2)} x_{k}}}=e^{X \beta^{(2)}}(2)
$$

Thus, the exponential of the coefficient is the RRR for a one-unit change in the corresponding variable. This is easily interpreted as the ratio of the probability of choosing one outcome category divided by the probability of choosing the baseline category. ${ }^{3738}$

\section{Patient and public involvement}

Patients and the public will be involved in the dissemination plan.

\section{RESULTS}

In all, 16448 of the 21785 women who provided information about their most recent pregnancy during the 5 years preceding the survey made at least one ANC visit.

\section{Timing of first ANC contact}

About 16448 (75\%) of all the respondents reported that they had at least one ANC contact during their most recent pregnancies. Among which $24 \%$ started such visits in the first trimester, $63 \%$ in the second trimester and others in the last trimester (table 1 and figure 2). Nearly one-fifth (19.4\%) of women aged 15-19 years started ANC visits early (first trimester), $15 \%$ among women with no education, $20 \%$ of women whose spouses alone decided healthcare utilisation and $18 \%$ among the women with no media exposure. Also, 13\% of the Hausa/Fulani women started ANC during the first trimester, $18 \%$ among women from low wealth households, $19 \%$ among unemployed women, $19 \%$ among the North-Eastern women, $19 \%$ among the North-Western women and 22\% among the rural women as shown in table 1 . All the explanatory variables considered were significantly $(p<0.001)$ associated with the trimester of the first ANC visit except the age of mothers and marital status. Further analysis showed a significant association between the number of ANC contacts made and the timing of initiation of such contacts with a higher number of contacts among those that initiated ANC during the first trimester. The median number of ANC contacts was $4(\mathrm{IQR}=0-20)$. About $45 \%$ of those that had eight or more contacts started in the first trimester 
Table 1 Association between respondents' characteristics and timing of first ANC visit

Trimester of first ANC visit (\%)

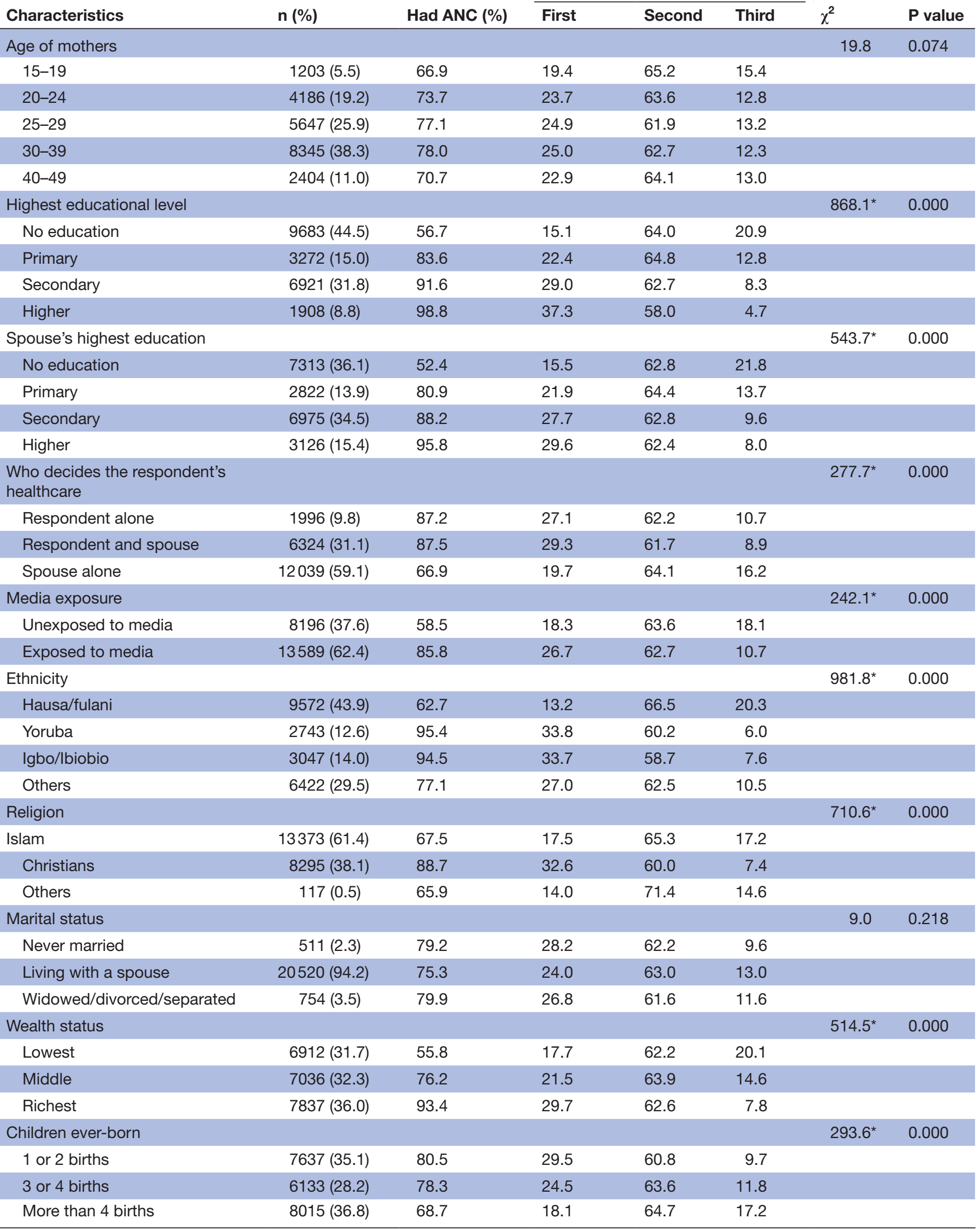

Continued 
Open access

Table 1 Continued

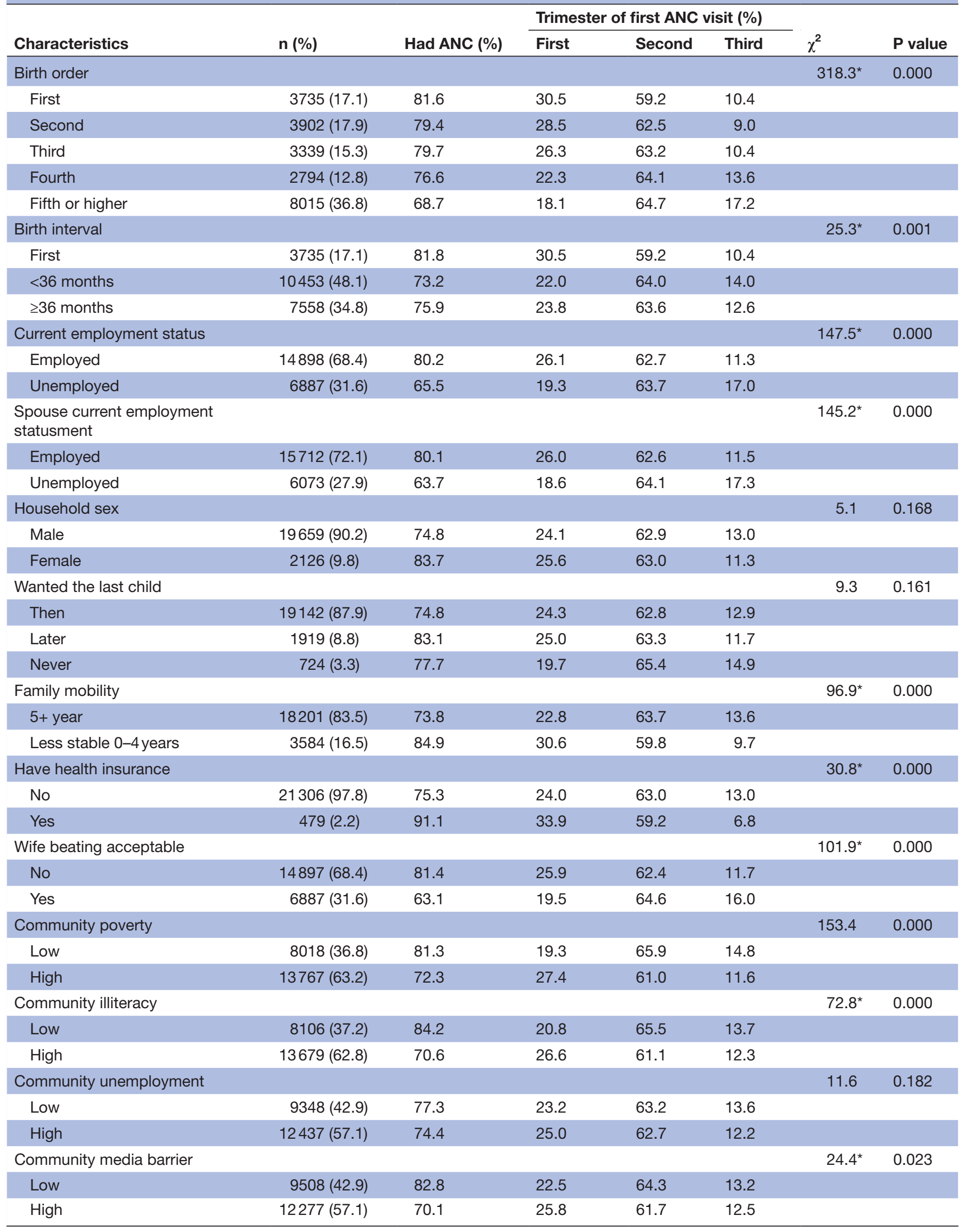


Table 1 Continued

\begin{tabular}{|c|c|c|c|c|c|c|c|}
\hline \multirow[b]{2}{*}{ Characteristics } & \multirow[b]{2}{*}{ n (\%) } & \multirow[b]{2}{*}{ Had ANC (\%) } & \multicolumn{3}{|c|}{ Trimester of first ANC visit (\%) } & \multirow[b]{2}{*}{$\chi^{2}$} & \multirow[b]{2}{*}{$P$ value } \\
\hline & & & First & Second & Third & & \\
\hline Community SES disadvantage & & & & & & $713.6^{*}$ & 0.000 \\
\hline Middle & $7190(33.0)$ & 80.4 & 20.1 & 65.2 & 14.7 & & \\
\hline Highest & $7053(32.4)$ & 51.6 & 15.7 & 63.4 & 20.9 & & \\
\hline \multicolumn{8}{|l|}{ Region } \\
\hline North central & $3014(13.8)$ & 72.4 & 31.2 & 59.0 & 9.7 & 832.3 & 0.000 \\
\hline North East & $3841(17.6)$ & 71.5 & 19.4 & 64.2 & 16.4 & & \\
\hline North West & 7602 (34.9) & 63.7 & 12.5 & 67.2 & 20.3 & & \\
\hline South East & $2126(9.7)$ & 96.2 & 32.4 & 59.0 & 8.6 & & \\
\hline South South & 2007 (9.2) & 82.0 & 28.5 & 63.0 & 8.5 & & \\
\hline Rural & $12126(60.2)$ & 66.2 & 21.6 & 63.2 & 15.3 & & \\
\hline Provider of ANC assistance & & & & & & $79.7^{*}$ & 0.000 \\
\hline Unskilled provider & 7671 (35.2) & 30.8 & 18.7 & 63.9 & 17.4 & & \\
\hline Skilled provider & $14114(64.8)$ & 99.9 & 25.2 & 62.8 & 12.1 & & \\
\hline Number of ANC contacts & & & & & & $3700.2^{*}$ & 0.000 \\
\hline None & 5365 (25.0) & 0.0 & - & - & - & & \\
\hline $1-3$ & $3793(17.7)$ & 100.0 & 6.4 & 53.8 & 39.8 & & \\
\hline $4-7$ & 8210 (38.3) & 100.0 & 20.3 & 73.1 & 6.5 & & \\
\hline $8+$ & 4097 (19.1) & 100.0 & 45.2 & 52.8 & 2.0 & & \\
\hline
\end{tabular}

${ }^{*}$ Significant $\chi^{2}$ at 0.05 .

ANC, antenatal care; SES, socioeconomic status.

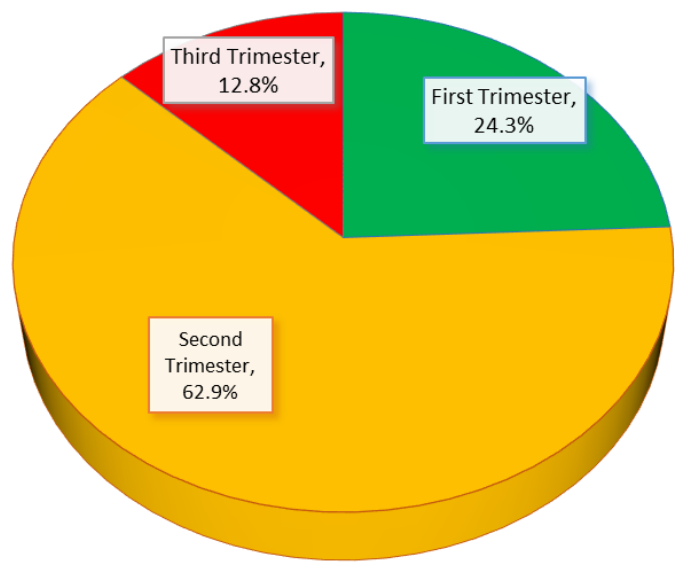

Figure 2 Distribution of the trimester of first ANC visit among those who had any ANC contact. ANC, antenatal care. compared with only $6.4 \%$ among those that had less than four contacts.

Osun state had the highest $(98.8 \%)$ level of ANC utilisation and the lowest $(36.3 \%)$ in Zamfara as shown in figure 3 and table 2 .

The proportion of women who started ANC in the first trimester was highest in Benue (44.5\%), Lagos $(41.4 \%)$ and Nasarawa (39.3\%) and lowest in Zamfara $(7.6 \%)$, Kano $(7.4 \%)$ and Sokoto $(4.8 \%)$ as shown in table 2 and figure 4. Overall, 10 states and 27 States had 0\%-33\% and $34 \%-65 \%$ of the women starting ANC visits during the first trimester, respectively (figure 4).

\section{Correlates of the onset of ANC visits}

During the pregnancy, mothers aged 40-49 years (adjusted RRR (aRRR): 1.65, 95\% CI: 1.10 to 2.45) were $65 \%$ more likely to initiate ANC during the first trimester of pregnancy relative to those aged 15-19 years (table 3). Respondents with higher education and secondary 


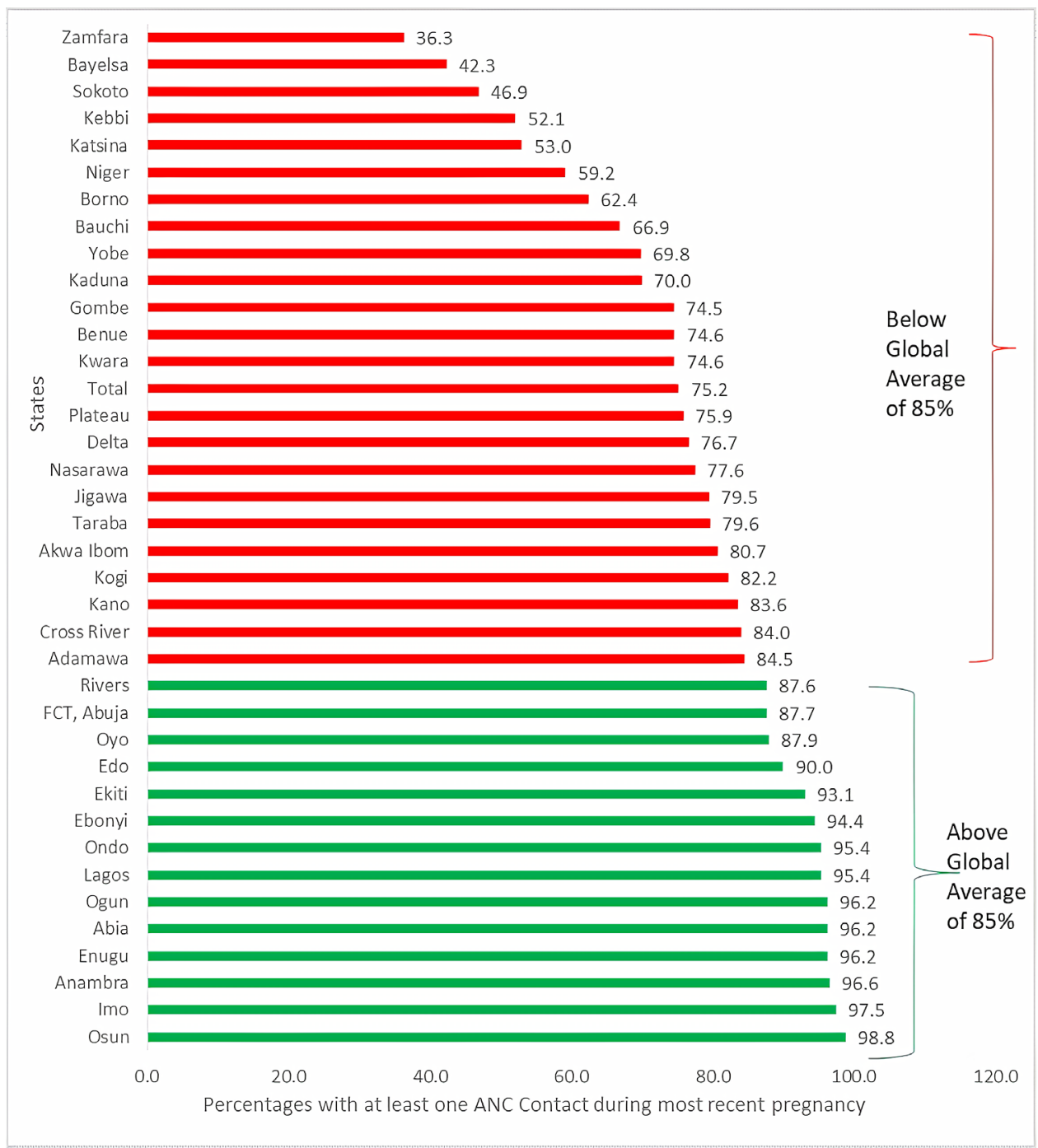

Figure 3 Distribution of women with at least one ANC contact during most recent pregnancy by state. ANC, antenatal care.

education were 2.6 times, and 1.4 times, respectively, more likely to initiate ANC contact during the first trimester than those with no education. Mothers in North Central were 2.4 times, North East and South-East were approximately 1.6 times each and South West 2.7 times more likely to start ANC in the first trimester than mothers from the North West. Also, respondents from the households in the richest wealth category were more likely to initiate ANC in the first trimester compared with those from households in the poorest wealth tertile (aRRR: 1.49, $95 \%$ CI: 1.21 to 1.85 ). Other significant variables are spouse education, ethnicity, religion and birth order. Women who participate in her healthcare utilisation were 4\% (aRRR: $1.04,95 \%$ CI: 0.90 to 1.20 ) times more likely to have early initiation of ANC.

\section{DISCUSSION}

This study assessed compliance with WHO ANC guidelines on the timing of the first ANC contact in Nigeria. We found that only one-quarter of the pregnant women met the new WHO recommendation on the initiation of ANC contacts during the first trimester. This is very low and could slow the progress towards the attainment of SDG targets in maternal and childhood health in Nigeria. This estimate is lower than the reported $40.6 \%$ in Ethiopia, ${ }^{35}$ and the average of $44.3 \%$ found among pregnant women in 54 low-income and medium-income countries between 2012 and 2018. ${ }^{34}$ The level of early ANC contact in Nigeria is similar to the $24.9 \%$ average in SSA, and lower than the average for the countries in the developing regions $(48.1 \%)$, the $64.3 \%$ global rate, and the $84.8 \%$ in the developed countries. ${ }^{36}$ This study also showed that relationship existed between sociodemographic characteristics of the women and the timing of ANC contacts. The associated factors with the timely initiation of ANC contact are maternal age, maternal education, spouse education, household wealth quintiles and region of residence, ethnicity, religion and birth order. We found a high number of ANC contacts, as many as 20 ANC contacts made, among those that started ANC in the first trimester. This could be attributed to the fact that ANC clinics hold every week in most hospitals that offer 
Table 2 Distribution of onset of ANC visits during most recent pregnancy by states

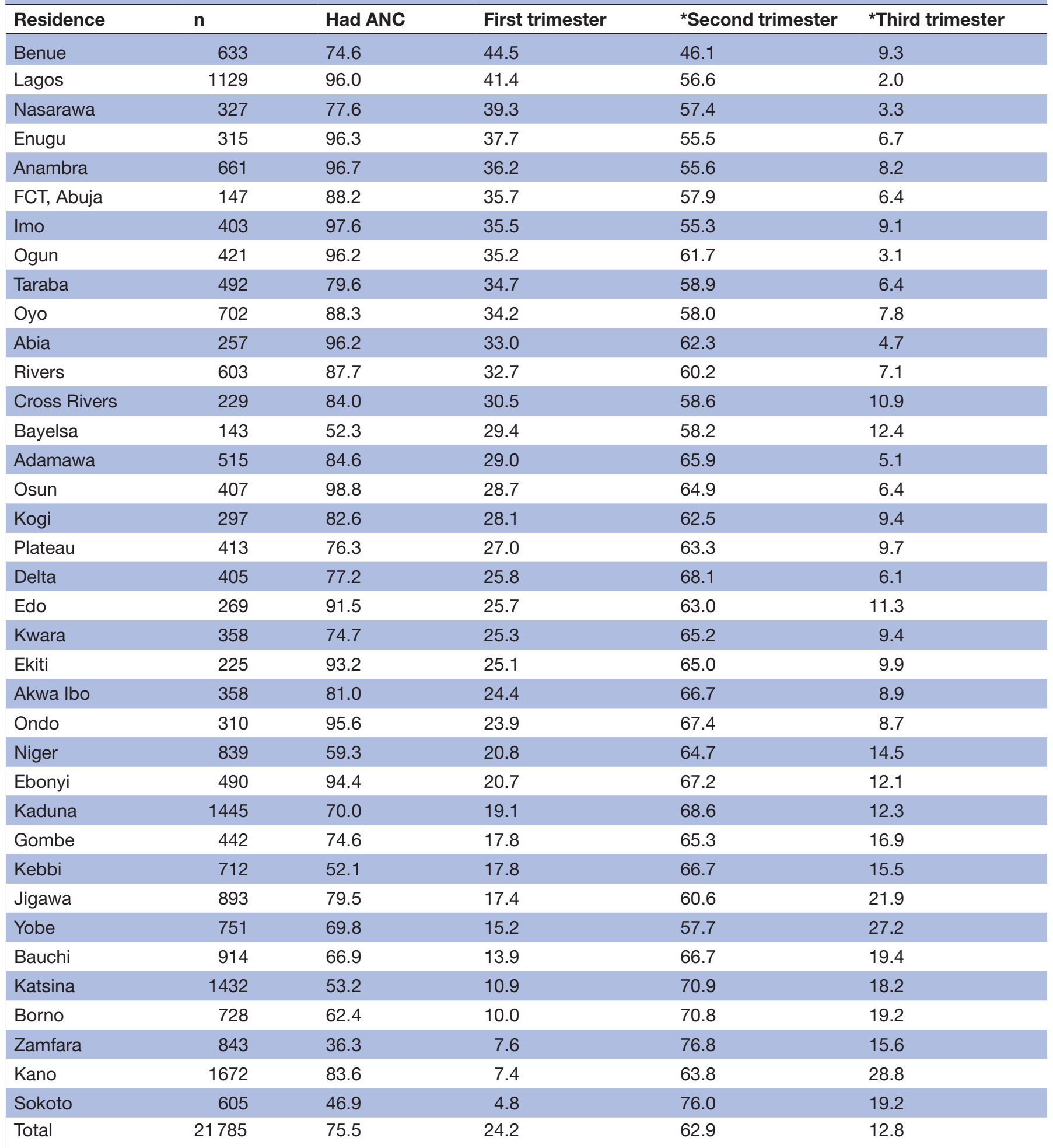

*Ordered using the first trimester.

ANC, antenatal care.

ANC services in Nigeria. Therefore, a woman that started ANC contact in the first trimester may have more than 20 ANC contacts.

The couple's level of education had similar effects on the timing of the first ANC visit. Women's and husbands' educational levels higher than secondary school were associated with initiating ANC visits during the first trimester; while lower educational levels were related to making first ANC contact at a later stage of pregnancy. In India and other settings, women with higher education were more 


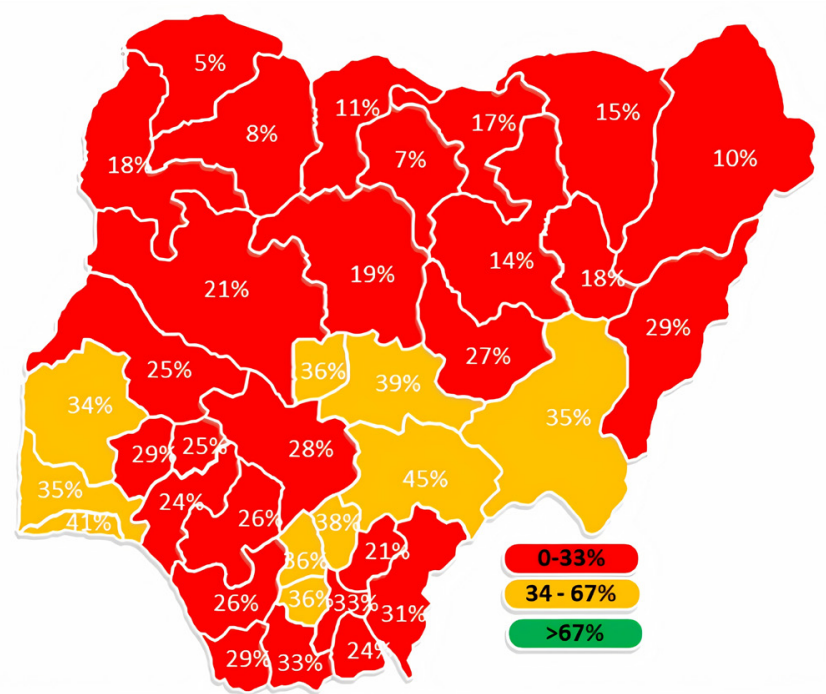

Figure 4 Distribution of women that initiated ANC contact within first trimester by states in Nigeria. ANC, antenatal care.

likely to start ANC visits during the first trimester. ${ }^{20}$ In Uganda, husbands' level of education was positively associated with early ANC visits. ${ }^{28}$

The initiation of first ANC contact was more delayed beyond the first trimester among women whose healthcare decision was the prerogative of the husbands compared with women who made such decisions alone and those who were making joint decisions with their husbands. In Uganda, educated husbands contributed to early booking, while husbands' fear of discovery of their positive HIV status contributed to the late booking. ${ }^{28}$ Husbands in Ethiopia were an important factor in encouraging their spouses to go for their first ANC visit. ${ }^{27}$

The current study showed the importance of media in propagating messages on the need for and timely initiation of ANC resources. Our study reaffirms the findings of a previous study ${ }^{39}$ that linked ANC attendance to media exposure. As previously noted by Fagbamigbe $e t a l$, this study reaffirms that media exposure is a predictor for initiation of ANC utilidation. ${ }^{26}$ More women who were exposed to media initiated first ANC contacts during the first trimester than those who had no media exposure. However, the association was not significant in the adjusted model. A similar finding has been reported elsewhere. $^{3440}$

Our findings, also, indicate that the proportion of ANC visits initiated during the first trimester was lowest among Hausa/Fulani women. Low initiation of ANC contacts during the first trimester by Hausa/Fulani women could probably be due to a high level of illiteracy, early marriage, lower media exposure and the largely patriarchal nature of northern society which may hinder health-seeking behaviour among Hausa/Fulani women. These factors have been previously described to influence healthseeking behaviours of married women among this ethnic group ${ }^{41}$ Interethnic differences in ANC utilisation has been reported in the literature. ${ }^{23} 3443$ Access to care, a function of availability of healthcare services, which is directly related to proximity to ANC services could have influenced this finding. Literature has shown that the person/hospital ratio and person/doctor ratio is lower in the Northern region ${ }^{44}$ which is predominantly occupied by the Hausa/Fulanis. Besides, the wave of insurgencies and displacement in the North-East part of Nigeria could have limited the access to ANC care. ${ }^{45}$

Nonetheless, the existing health system in Nigeria could have directly or indirectly influenced the timing of ANC initiation in the country. Although the Federal Government of Nigeria provides guidelines and support, ANC utilisation through maternal health programming is the primary responsibility of the state governments. Each state government is responsible for the provision of health facilities and the human resources to adequately provide ANC services. It is therefore not known if the current Nigerian health system capacity could handle the heavier ANC demands that could be a direct consequence of early initiation of ANC, as per the WHO recommendations. While it is important to have early ANC contacts, there are urgent needs to ensure that the health system is equipped to meet potential higher demands. Therefore, to ensure that women have early initiation of ANC and sufficient numbers of contacts, there are needs to provide accessible ANC health facilities equipped with welltrained and qualified health professionals. We, therefore, suggest a further study on structural factors of the health system that could influence the timing of ANC initiation.

The proportion of women who initiated first ANC contact during the first trimester were higher among Catholics and other Christians compared with other religious affiliations. It is more common among the Islamic faith adherents than other religious worshippers to submit to nature when it comes to issues such as health and well-being. This position has been noted to be higher in Northern Nigeria where Islam is more dominant. ${ }^{43}$ Thus, the Islam religion may be negatively impacting health-seeking behaviour of Muslim pregnant women in Nigeria. The impact of religion on ANC utilisation may be more effectively studied by comparing ANC utilisation statistics within regions, as national statistics may be skewed by regional disparities in access to health.

The likelihood of ANC initiation during the first trimester was higher among the currently employed women. Employed women and those whose husbands were currently employed were more likely to start ANC earlier than the other categories of women. These results are similar to findings in Colombia where women in clerical and professional jobs were more likely to start ANC visits in the first trimester. ${ }^{30}$ The proportion of women who initiated ANC contacts during the first trimester were higher in the urban areas than in the rural areas but these differences were insignificant in the adjusted model. Also, a higher proportion of those who contacted skilled ANC providers, initiated ANC visits during the first trimester than those who patronised unskilled providers. Similarly, the odds of early initiation of ANC during the first trimester was higher among women from households 
Table 3 Adjusted relative risk ratios of the factors associated with the timing of initiation of ANC contact (NDHS 2018)

\section{Characteristics}

\section{Age of mothers}

15-19

20-24

25-29

30-39

40-49

Highest educational level

\begin{tabular}{l} 
No education \\
Primary \\
Secondary \\
Higher \\
Spouse's highest education \\
No education \\
\hline Primary \\
\hline Secondary \\
\hline Higher \\
\hline Who decides respondent's healthcare \\
\hline Respondent alone \\
\hline Respondent and Spouse \\
\hline Spouse alone \\
\hline Media exposure \\
\hline Exposed to media \\
\hline Ethnicity \\
\hline Hausa/Fulani \\
\hline Yoruba \\
\hline Igbo/lbiobio \\
\hline Others
\end{tabular}

Early initiation (First trimester) aRRR $(95 \% \mathrm{Cl})$

Reference

1.16 (0.85 to 1.58$)$

1.04 (0.75 to 1.45$)$

1.34 (0.94 to 1.90$)$

1.66 (1.12 to 2.48$)$

sig

0.34

0.79

0.11

0.01
Reference

1.26 (1.03 to 1.53 )

1.51 (1.23 to 1.86$)$

2.63 (1.86 to 3.71 )

Reference

1.05 (0.86 to 1.29$)$

1.29 (1.06 to 1.56$)$

1.28 (1.01 to 1.63 )

1.04 (0.83 to 1.28$)$

1.04 (0.90 to 1.20$)$

Reference

1.07 (0.92 to 1.24$)$

Reference

1.29 (0.9 to 1.85$)$

1.81 (1.21 to 2.71 )

1.66 (1.35 to 2.03 )

Reference

Islam

Other Christians

Others

Wealth status

Low

Middle

Richest

Birth order

\begin{tabular}{lllll}
\hline 1 & $1.90(1.44$ to 2.52$)$ & 0.00 & $1.33(1.03$ to 1.71$)$ & 0.03 \\
\hline 2 & $1.77(1.41$ to 2.22$)$ & 0.00 & $1.44(1.17$ to 1.76$)$ & 0.00 \\
\hline 3 & $1.66(1.34$ to 2.04$)$ & 0.00 & $1.36(1.13$ to 1.64$)$ & 0.00 \\
\hline 4 & $1.21(0.99$ to 1.48$)$ & 0.06 & $1.18(1.01$ to 1.40$)$ & 0.04 \\
\hline+ & Reference & & & \\
$\begin{array}{l}\text { Birth interval } \\
\text { First birth }\end{array}$ & $1.19(1.04$ to 1.52$)$ & 0.01 & $1.23(1.03$ to 1.51$)$ & 0.04 \\
$<36$ months & $0.95(0.83$ to 1.09$)$ & 0.45 & $0.97(0.86$ to 1.08$)$ & 0.54 \\
\hline $36+$ months & Reference & & & \\
\hline
\end{tabular}

Late initiation (Second trimester) aRRR $(95 \% \mathrm{Cl}) \quad$ sig

sig

0.62

$1.00(0.76$ to 1.33$) \quad 0.98$

1.19 (0.88 to 1.62$) \quad 0.26$

1.34 (0.95 to 1.89$)$

0.10

0.10

$\begin{array}{lll}0.02 & 1.11(0.94 \text { to } 1.30) & 0.21 \\ 0.00 & 1.28(1.07 \text { to } 1.54) & 0.01 \\ 0.00 & 1.92(1.40 \text { to } 2.63) & 0.00\end{array}$

$\begin{array}{lll}0.62 & 1.14(0.97 \text { to } 1.35) & 0.11 \\ 0.01 & 1.20(1.03 \text { to } 1.41) & 0.02 \\ 0.04 & 1.18(0.96 \text { to } 1.45) & 0.11\end{array}$

0.75

1.06 (0.87 to 1.28$)$

0.57

$0.64 \quad 1.05(0.92$ to 1.20$) \quad 0.46$


Table 3 Continued

\begin{tabular}{|c|c|c|c|c|}
\hline \multirow{2}{*}{$\begin{array}{l}\text { Characteristics } \\
\text { Age of mothers }\end{array}$} & \multicolumn{2}{|c|}{ Early initiation (First trimester) } & \multicolumn{2}{|c|}{ Late initiation (Second trimester) } \\
\hline & aRRR (95\% CI) & sig & aRRR (95\% Cl) & sig \\
\hline \multicolumn{5}{|c|}{ Current employment status } \\
\hline Employed & 1.14 (0.85 to 1.52$)$ & 0.37 & 1.25 (0.97 to 1.60$)$ & 0.08 \\
\hline \multicolumn{5}{|c|}{ Spouse current employment status } \\
\hline Employed & $1.16(0.86$ to 1.57$)$ & 0.34 & 0.97 (0.75 to 1.25$)$ & 0.83 \\
\hline \multicolumn{5}{|l|}{ Region } \\
\hline North West & Reference & & & \\
\hline North central & 2.60 (2.04 to 3.31$)$ & 0.00 & $1.32(1.08$ to 1.62$)$ & 0.01 \\
\hline North East & 1.58 (1.30 to 1.93$)$ & 0.00 & 1.21 (1.04 to 1.40$)$ & 0.02 \\
\hline South East & 1.79 (1.15 to 2.81$)$ & 0.01 & $1.15(0.76$ to 1.74$)$ & 0.51 \\
\hline South South & 1.55 (1.10 to 2.18$)$ & 0.01 & 1.06 (0.78 to 1.44$)$ & 0.70 \\
\hline South West & 3.01 (2.06 to 4.39$)$ & 0.00 & 1.64 (1.17 to 2.31$)$ & 0.00 \\
\hline \multicolumn{5}{|l|}{ Residence } \\
\hline Urban & 0.80 (0.69 to 0.93$)$ & 0.00 & 0.93 (0.81 to 1.06$)$ & 0.28 \\
\hline \multicolumn{5}{|l|}{ Household head sex } \\
\hline Female & 0.79 (0.63 to 0.99$)$ & 0.04 & 0.90 (0.74 to 1.10$)$ & 0.30 \\
\hline \multicolumn{5}{|l|}{ Wanted the last child } \\
\hline Then & Reference & & & \\
\hline Later & 0.68 (0.55 to 0.85$)$ & 0.00 & 0.77 (0.63 to 0.93 ) & 0.01 \\
\hline Never & 0.47 (0.34 to 0.65$)$ & 0.00 & 0.69 (0.52 to 0.91$)$ & 0.01 \\
\hline \multicolumn{5}{|l|}{ Family mobility } \\
\hline Less stable $0-4$ years & $0.96(0.81$ to 1.14$)$ & 0.67 & 0.94 (0.80 to 1.10$)$ & 0.43 \\
\hline \multicolumn{5}{|l|}{ Have health Insurance } \\
\hline Yes & $1.42(0.92$ to 2.21$)$ & 0.11 & $1.20(0.80$ to 1.81$)$ & 0.38 \\
\hline \multicolumn{5}{|l|}{ Wife beating acceptable } \\
\hline No & 1.11 (0.97 to 1.27$)$ & 0.13 & 1.03 (0.92 to 1.16$)$ & 0.59 \\
\hline \multicolumn{5}{|c|}{ Community SES disadvantage } \\
\hline Lowest & 0.82 (0.61 to 1.09$)$ & 0.17 & $0.92(0.72$ to 1.18$)$ & 0.51 \\
\hline Middle & 0.81 (0.67 to 0.99$)$ & 0.04 & 0.91 (0.78 to 1.06$)$ & 0.23 \\
\hline Highest & Reference & & & \\
\hline
\end{tabular}

All the variables in this table were significant at $p<0.02$ in the bivariable analysis aRRR.

ANC, antenatal care; aRRR, adjusted relative risk ratio; NDHS, Nigeria Demographic Health Survey; SES, socioeconomic status.

in the higher wealth quintiles. In a comparison study, Kuuire et al found that urban women with a high wealth index were more likely to initiate ANC contacts during the recommended first trimester than their counterparts in poor rural areas. ${ }^{23}$

Despite the stark reality that ensuring compliance on first ANC contact during the first trimester of pregnancy is very key to attaining positive maternal and infant health outcomes afterwards, the available evidence in the current study and the reported findings from many countries with similar maternal and infant health indicators as Nigeria show that high percentage of pregnant women who had any ANC contact started such contact later than the prescribed first trimester. For instance, studies in South and North Ethiopia reported that less than a fifth and about a third respectively made first ANC contacts during the recommended first trimester. ${ }^{27}{ }^{46}$ Also, it was reported that the majority of pregnant women in Tanzania made initial ANC contact later than the first trimester. ${ }^{47}$ Similarly, pregnant women in Nigeria have been reported to initiate first ANC contact at a later gestational stage than the recommended first trimester. For instance, some earlier studies in Nigeria found that most pregnant women who attended ANC reported delayed initiation till second and third trimester. ${ }^{2648}$

We found significant variations and inequalities in the proportion of women who initiated ANC contacts during the first trimester across the states in Nigeria. While the 
proportion who started ANC contacts was high in states such as Benue $(44.5 \%)$, Lagos $(41.4 \%)$ and Nasarawa the levels were lower than $10 \%$ in Zamfara, Kano and Sokoto States which achieved less than 2\%. Overall, 10 states had $0 \%-33 \%$ while 27 states attained $34 \%-65 \%$ ANC initiation during the first trimester. In general, we found the lowest ANC uptake and delayed initiation of ANC contacts among the States in Northern Nigeria compared with the Southern States.

The current study has some limitations. Recall bias might have set in as some respondents were illiterate and most respondents had to recall when they initiated ANC contacts, except for few cases that were found on ANC cards. The identified factors were only associated with the timing of ANC contacts and should not be interpreted as the causes. Our choice of explanatory variables was limited by the secondary nature of the data. We assumed that there are primary healthcare facilities in each locality or area in Nigeria where ANC services are accessible. However, this may not be so. The closeness and availability of healthcare facilities and women's access to them can influence the initiation of ANC contact.

However, our findings are generalisable as the sample used in this study was nationally representative of women of reproductive age in Nigeria. More so, the data source has been reported in different studies to use rigorously tested collection tools and procedures as well as trained personnel on questionnaire administration. Our study is novel in providing a subnational (state-level) analysis of adherence to the timeliness of ANC contacts as stipulated in the WHO guidelines.

\section{CONCLUSIONS}

Only a quarter of pregnant women who had any ANC contact initiated such contacts during the first trimester with wider disparities across the states in Nigeria and across the background characteristics of the pregnant women. The level of the achievement of the WHO recommended initiation of ANC contacts during the first trimester was poor and were influenced by different factors. The main drivers of the timeliness of ANC initiation are maternal age and education, spouse education, household wealth quintiles, the region of residence, ethnicity, religion and birth order. Notably is the wide gap in the rate of early initiation of ANC contacts among the Northern and the Southern states.

\section{Recommendations}

There are needs for both local, state and national governments to adopt, embrace and implement the WHO recommendations on ANC utilisation, especially the initiation of the contacts during the first trimesters. Early ANC booking is an antedote for having the optimal number of ANC contacts. Concerted efforts from all stakeholders on maternal and child healthcare are necessary to change the practices of late initiation of ANC contacts in Nigeria. Efforts should be made to promote early enrolment of
ANC services, as well as create awareness among the populace for optimal utilisation of ANC. Interventions to improve ANC attendance should also target barriers linked with inequities and inequalities in ANC utilisation as related to geographical place of residence. Currently, the North lags behind in early ANC initiation. There are needs for the ANC stakeholders in those Northern states to benchmark what is been done right in the Southern states with higher rates of early initiation. Although our study did not explore the assessment of existing health systems in Nigeria, the government and other stakeholders at the state levels need to ensure that the health system is equipped to meet the higher demands that could be occasioned by the early initiation of ANC in Nigeria. Besides, there is a need for further study of the Nigerian health system on its capacity and the influence it may have on the timing of ANC initiation.

Acknowledgements The authors thank the ICF for granting access to the dataset. Contributors AFF conceptualised the study, designed the study, AFF analysed the data, provided the visualisations and wrote the results. 00 searched the literature while $\mathrm{OF}$ contributed to visualisation of findings. All authors contributed to literature search, data interpretation, writing of the manuscript. All authors read and approved the manuscript.

Funding The authors have not declared a specific grant for this research from any funding agency in the public, commercial or not-for-profit sectors.

Map disclaimer The inclusion of any map (including the depiction of any boundaries therein), or of any geographic or locational reference, does not imply the expression of any opinion whatsoever on the part of BMJ concerning the legal status of any country, territory, jurisdiction or area or of its authorities. Any such expression remains solely that of the relevant source and is not endorsed by BMJ. Maps are provided without any warranty of any kind, either express or implied.

Competing interests None declared.

Patient and public involvement Patients and/or the public were not involved in the design, or conduct, or reporting, or dissemination plans of this research.

Patient consent for publication Not applicable.

Ethics approval Ethics approval was obtained from the ICF Institutional Review Board, US (Number FWA000008450) by the ICF International, the owners of the population-based secondary DHS datasets. We were granted full access to use the data by ICF International with authorisation letter 144644. Duly signed informed consent to participate was obtained from all consenting participants before the interview started. Further information on the data and ethical considerations are available at dhsprogram.com. All methods were carried out in accordance with relevant guidelines and regulations.

Provenance and peer review Not commissioned; externally peer reviewed.

Data availability statement Data are available in a public, open access repository. The anonymised data are available in the public domain. The data supporting this article is available on request at www.dhsprogram.com. Extra data are available by emailing Bridgette Wellington (thedhsprogram@gmail.com) the Data Archivist.

Open access This is an open access article distributed in accordance with the Creative Commons Attribution Non Commercial (CC BY-NC 4.0) license, which permits others to distribute, remix, adapt, build upon this work non-commercially, and license their derivative works on different terms, provided the original work is properly cited, appropriate credit is given, any changes made indicated, and the use is non-commercial. See: http://creativecommons.org/licenses/by-nc/4.0/.

ORCID iDs

Adeniyi Francis Fagbamigbe http://orcid.org/0000-0001-9184-8258

Omon Stellamaris Fagbamigbe http://orcid.org/0000-0003-1657-2006 


\section{REFERENCES}

1 UNICEF. Antenatal care. 1-9, 2019. Available: https://data.unicef.org/ topic/maternal-health/antenatal-care/\#

2 WHO, UNICEF, UNFPA, World Bank Group and the United Nations Population Division. Trends in maternal mortality: 2000 to 2017: estimates by WHO, UNICEF, UNFPA, World Bank Group and the United Nations Population Division. Geneva: World Health Organization, 2019.

3 WHO, UNICEF, UNFPA, World Bank Group \& United Nations Population Division. Trends in maternal mortality 1990 to 2015, 2015.

4 United Nations Inter-agency Group. United Nations Inter-agency Group for Child Mortality Estimation (UN IGME), 'Levels \& Trends in Child Mortality: Report 2018. 1-44, 2018.

5 WHO. WHO maternal mortality report., 20201. Available: https:// www.who.int/news-room/fact-sheets/detail/maternal-mortality

6 Alkema L, Chou D, Hogan D, et al. Global, regional, and national levels and trends in maternal mortality between 1990 and 2015 with scenario-based projections to 2030: a systematic analysis by the un maternal mortality estimation Inter-Agency group. Lancet 2016;387:462-74.

7 United Nations. Sustainable development goals (SDG), 2015. Available: http://www.un.org/sustainabledevelopment/sustainabledevelopment-goals/

8 UNICEF. UNICEF strategy for health 2016-2030, 2015: 1-256.

9 Danzhen Y, Hug L, Ejdemyr S. Child mortality 2015. UNICEF, WHO, World Bank Gr. United Nations, 2015.

10 Atuhaire S, Mugisha JF. Determinants of antenatal care visits and their impact on the choice of birthplace among mothers in Uganda: a systematic review. Obstet Gynecol Int J 2020;11:77-81.

11 Ganchimeg T, Ota E, Morisaki N, et al. Pregnancy and childbirth outcomes among adolescent mothers: a World Health Organization multicountry study. BJOG 2014;121:40-8.

12 Say L, Chou D, Gemmill A, et al. Global causes of maternal death: a WHO systematic analysis. Lancet Global Health 2014;2:e323-33.

13 Chou D, Daelmans B, Jolivet RR, et al. Ending preventable maternal and newborn mortality and stillbirths. BMJ 2015;351:h4255-22.

14 Althabe F, Moore JL, Gibbons L, et al. Adverse maternal and perinatal outcomes in adolescent pregnancies: the global network's maternal newborn health registry study. Reprod Health 2015;12:S8.

15 Fagbamigbe AF, Idemudia ES. Barriers to antenatal care use in Nigeria: evidences from non-users and implications for maternal health programming. BMC Pregnancy Childbirth 2015;15:1-10.

16 Lassi ZS, Mansoor T, Salam RA, et al. Essential pre-pregnancy and pregnancy interventions for improved maternal, newborn and child health. Reprod Health 2014;11:S2.

17 Ogu RN, Alegbeleye JO. Improving maternal health:Women's attitude to antenatal care utilization is crucial. Clin Obstet Gynecol Reprod Med 2018:4:1-3.

18 Onyeajam DJ, Xirasagar S, Khan MM, et al. Antenatal care satisfaction in a developing country: a cross-sectional study from Nigeria. BMC Public Health 2018;18:1-9.

19 WHO. WHO recommendations on antenatal care for a positive pregnancy experience, 2016. Available: https://www.who.int/ reproductivehealth/publications/maternal_perinatal_health/ancpositive-pregnancy-experience/en/

20 Gupta R, Talukdar B. Frequency and timing of antenatal care visits and its impact on neonatal mortality in eag states of India. J Neonatal Biol 2017:06.

21 Geta MB, Yallew WW. Early initiation of antenatal care and factors associated with early antenatal care initiation at health facilities in southern Ethiopia. Adv. Public Heal 2017;2017:1-6.

22 Aliyu AA, Dahiru T. Predictors of delayed antenatal care (ANC) visits in Nigeria: secondary analysis of 2013 Nigeria demographic and health survey (NDHS). Pan Afr Med J 2017;26:124.

23 Kuuire VZ, Kangmennaang J, Atuoye KN, et al. Timing and utilisation of antenatal care service in Nigeria and Malawi. Glob Public Health 2017;12:711-27.

24 Filippi V, Chou D, Ronsmans C. Levels and causes of maternal mortality and morbidity. Dis. control priorities, third ed. Reprod Matern Newborn Child Heal 2016;2:51-70.

25 Abuka T, Alemu A, Birhanu B. Assessment of timing of first antenatal care Booking and associated factors among pregnant women who attend antenatal care at health facilities in Dilla town, Gedeo zone, southern nations, Nationalities, and peoples region, Ethiopia, 2014 $J$ Pregnancy Child Health 2016;3.

26 Fagbamigbe AF, Abel C, Mashabe B, et al. Survival analysis and prognostic factors of the timing of first antenatal care visit in Nigeria. Adv Integr Med 2019;6:110-9.

27 Gebremeskel F, Dibaba Y, Admassu B. Timing of first antenatal care attendance and associated factors among pregnant women in Arba Minch town and Arba Minch district, Gamo Gofa zone, South Ethiopia. J Environ Public Health 2015;2015:1-7.

28 McAllister JM. HHS public access. Physiol Behav 2015;176:139-48.

29 Warri D, George A. Perceptions of pregnant women of reasons for late initiation of antenatal care : a qualitative interview study 2020;0:1-12.

30 Osorio AM, Tovar LM, Rathmann K. Individual and local level factors and antenatal care use in Colombia: a multilevel analysis. Cad Saude Publica 2014;30:1079-92.

31 Fagbamigbe AF, Olaseinde O, Setlhare V. Sub-national analysis and determinants of numbers of antenatal care contacts in Nigeria: assessing the compliance with the $\mathrm{WHO}$ recommended standard guidelines. BMC Preg Child 2021;21:1-19.

32 National Population Commission(NPC) [Nigeria] \& ICF International. Nigeria demographic and health survey 2018, 2019.

33 Kuhnt J, Vollmer S. Antenatal care services and its implications for vital and health outcomes of children: evidence from 193 surveys in 69 low-income and middle-income countries. BMJ Open 2017;7:e017122.

34 Jiwani SS, Amouzou-Aguirre A, Carvajal L, et al. Timing and number of antenatal care contacts in low and middle-income countries: analysis in the countdown to 2030 priority countries. J Glob Health 2020;10:010502.

35 Kolola T, Morka W, Abdissa B. Antenatal care booking within the first trimester of pregnancy and its associated factors among pregnant women residing in an urban area: a cross-sectional study in Debre Berhan town, Ethiopia. BMJ Open 2020;10:e032960.

36 Moller A-B, Petzold M, Chou D, et al. Early antenatal care visit: a systematic analysis of regional and global levels and trends of coverage from 1990 to 2013. Lancet Glob Health 2017;5:e977-83.

37 Long JS, Freese J. Regression models for categorical dependent variables using stata (Stata Press), 2006.

38 Adhikari R, Podhisita C. Household headship and child death: evidence from Nepal. BMC Int Health Hum Rights 2010;10:13.

39 Ekpenyong MS, Bond C, Matheson D. Challenges of maternal and prenatal care in Nigeria. J Intensive Crit Care 2019;05.

40 Africa Progress panel. Maternal health: investing in the lifeline of healthy societies and economies (Policy Brief), 2010: 1-36.

41 Doctor H. V, Bairagi R, Findley SE. Northern Nigeria maternal, newborn and child health programme : selected analyses from population-based baseline survey. Open Demogr J 2011;4:11-21.

42 Doctor H. V. Nkhana-Salimu, S. \& Abdulsalam-Anibilowo, M. Health facility delivery in sub-Saharan Africa: Successes, challenges, and implications for the 2030 development agenda. BMC Public Health 2018;18:1-12.

43 McNabb M, Chukwu E, Ojo O, et al. Assessment of the quality of antenatal care services provided by health workers using a mobile phone decision support application in northern Nigeria: a pre/postintervention study. PLoS One 2015;10:e0123940.

44 Nwakeze NM, Kandala N. The spatial distribution of health establishments in Nigeria. African Popul Stud 2011;25:682-96.

45 Amodu OC, Richter MS, Salami BO. A scoping review of the health of Conflict-Induced internally displaced women in Africa. Int $J$ Environ Res Public Health 2020;17:1280-21.

46 Gudayu TW, Woldeyohannes SM, Abdo AA. Timing and factors associated with first antenatal care booking among pregnant mothers in Gondar Town; North West Ethiopia. BMC Preg Child 2014:14:2014.

47 Gross K, Alba S, Glass TR, et al. Timing of antenatal care for adolescent and adult pregnant women in south-eastern Tanzania. BMC Preg Child 2012;12:16.

48 Fagbamigbe AF, Mashabe B, Lepetu L, et al. Are the timings and risk factors changing? Survival analysis of timing of first antenatal care visit among pregnant women in Nigeria (2003 - 2013). Int J Womens Heal 2017;9:807-19. 